\title{
DIREITO DO TRABALHO E EMANCIPAÇÃO
}

\section{Murilo Carvalho Sampaio Oliveira"}

RESUMO: O presente artigo objetiva discutir quais as perspectivas emancipatórias para o juslaboralismo no cenário de crise do emprego, flexibilização, terceirização e precarização. Inicia contextualizando o cenário de crise no Direito do Trabalho para revisitar sua gênese, em busca de extrair sua ontologia emancipatória que é definida pelo seu caráter protetivo. Desenvolve dialeticamente a relação entre a proteção legal e emancipação, para a identificação de novas propostas emancipatórias para o Direito do Trabalho.

\section{INTRODUÇÃO}

Dizia Lacordaire "entre o forte e o fraco, entre o pobre e o rico, é a liberdade que escraviza, é a lei que liberta."(apud SUSSEKIND, 1981, p. 32). Esta frase, muito conhecida na seara do juslaboralismo, sinaliza

\footnotetext{
* Advogado, especialista em Direito do Trabalho, Mestrando em Direito Privado pela UFBA, Professor substituto de Direito do Trabalho da UFBA e da Faculdade de Ruy Barbosa. Membro do Instituto Baiano de Direito do Trabalho - IBDT e da Associação de Advogados de Trabalhadores Rurais - AATR-BA. murilosampaio@yahoo.com.br.
}

RÉSUMÉ: This article aims at discussing the emancipating perspectives on the Labour Law in the scenario of an unemployment crisis, as well as on flexibility, outsourcing and precariousness. Firstly, it contextualizes the scenario of the Labour Law in order to revise its genesis and emancipating nature, which is defined by its protective character. It develops the relationship between legal protection and emancipation dialectically for the identification of new emancipating proposals to the Labour Law.

um viés emancipatório articulado sobre a proteção legal-estatal. Indaga-se, então, o Direito do Trabalho e o seu caráter tutelar ao tempo que prega uma proteção-emancipação não termina por praticar uma dominação reguladora de uma efetiva emancipação?

Este ensaio objetiva percorrer esta indagação sem qualquer pretensão de resposta definitiva ou acabada. Pretende, em verdade, pontuar idéias e balizas que podem ajudar no caminho para a resposta.

Por dever acadêmico, cumpre, desde já, desvelar a pré-compreensão que envolve o ensaio, inclusive para publicizar os pré- 
juízos a fim de se evitar arbitrariedades (GADAMER, 2005). O olhar que construiu as idéias analisadas foi o olhar dialético materialista que considera a realidade em constante transformação e contraditória em si. Para a dialética, o conhecimento e a atividade humana estão inseridos num processo de totalização (MARX, 1996), que nunca alcança uma etapa definitiva, perfeita e acabada, estando em constante transformação. Talvez só a dialética possa assumir a dicotomia (contradição) emancipação-regulação inerente ao Direito do Trabalho.

O caminho seguido pelo ensaio perpassa a gênese do Direito Laboral com o fito de identificar a sua ontologia. Adiante, analisarse-á o contexto contemporâneo, em síntese apertada, para entender a crise do Direito do Trabalho. No cenário de crise, tratou-se de reafirmar uma posição protecionista. Ao final, cuidou dos pontos contraditórios do juslaboralismo e suas vertentes de regulação/ conservação e emancipação, anotando algumas direções.

\section{GÊNESE}

No estudo da gênese da disciplina laboral, acolhe-se a premissa de Mário De La Cueva, que vincula intrínseca e inseparavelmente o Direito do Trabalho à dignidade humana.

\footnotetext{
A história do Direito do Trabalho é um dos episódios na luta do homem pela liberdade, pela dignidade pessoal e social e pela conquista de um mínimo bem-estar, que, ao mesmo tempo dignifique a vida da pessoa humana, facilite e fomente o desenvolvimento da razão e da consciência. (DE LA CUEVA, 1969, p. 21)

O modo de produção capitalista difere substancialmente das demais e anteriores formas de organização da produção, pois
}

nele há separação entre aqueles que detêm os meios de produção dos outros que, somente tendo sua força de trabalho, sujeitam-se a vendê-la em troca de remuneração, a qual é muito aquém em relação à riqueza produzida pelo trabalho humano. Tem-se a divisão social do trabalho e a alienação. (MARX, 1978, p. 24)

A doutrina juslaboralista vincula essencialmente o surgimento do Direito do Trabalho ao movimento cunhado pela história como Revolução Industrial, iniciado pelo advento da máquina a vapor. Nesta linha, temos Orlando Gomes e Élson Gottschalk (2005), Rodrigues Pinto (2005), entre outros. Martins Catharino destoa ao afirmar que a origem do Direito do Trabalho não se limita à Revolução Industrial, mas à conjunção desta com o fenômeno chamado de questão social (hipossuficiência e consciência de classe). Poder-se-ia associar o surgimento deste ramo jurídico com a conjugação de três elementos: Revolução Industrial; Liberalismo; Consciência de Classe.

A Revolução Industrial implicou estruturais mudanças na forma de organizar a produção, engendrando uma categoria de trabalhadores que venderiam sua força de trabalho. A filosofia liberalista incentivava a total liberdade nas relações privadas, sem qualquer intervenção estatal. Nas relações de trabalho, a autonomia da vontade acarretou contratos leoninos e atentatórios à dignidade do trabalhador, visto que este - tendo no trabalho seu meio de sobrevivência - não estaria em condições de negociar os termos do contrato de trabalho, relegando ao empregador a definição do seu conteúdo. Isto foi denominado por Alfredo Palacios 
como Liberdade Liberticida. (SUSSEKIND, 2004, p.15).

Diante dessa situação, a concentração das massas de trabalhadores produziu, pela similitude das condições de vida, uma consciência coletiva, uma consciência de classe. As péssimas condições de trabalho conclamavam os trabalhadores à luta, eis que nada tinham a perder perante a dificuldade que viviam. "O Direito do Trabalho é obra desses homens que se perderam, por já não terem o que perder" (VIANA, 2004, p. 261). Então, a partir da organização coletiva, a luta reivindicatória consorciada com a utilização do máximo instrumento de pressão dos trabalhadores-a greve-ocasionou um processo de conquistas, normativizações no plano coletivo. Posteriormente, a influência da Igreja Católica simbolizada na encíclica Rerum Novarum, aliada a concepções humanistas, ensejaram o sentimento da questão social, estabelecendo o esteio para a atuação legislativa do Estado, mediante intervenção nas relações de trabalho com regulamentações protetivas dos hipossuficientes.

Não obstante o Direito Laboral ter surgido como conquista da ação organizada dos trabalhadores na Europa, suas características no Brasil são bastante distintas, uma vez que, no sistema brasileiro, a iniciativa estatal predominou, configurando um modelo de normatização autoritário corporativo (GODINHO, 2004, p. 120). Todavia, deve-se lembrar que o seu início foi demarcado por uma incipiente organização sindical, sob inspiração da ideologia anarquista proveniente da formação política dos imigrantes europeus que compunham parte considerável dos trabalhadores no Brasil. Logo, a afirmação de que o Direito do Trabalho no Brasil representou uma dádiva da lei não pode ser propalada, uma vez que não se coaduna, de forma fidedigna, com a história.

Já se disse não sem certa razão, que nosso Direito do Trabalho tem sido uma dádiva da lei, uma criação de cima para baixo, em sentido vertical. Em muitos casos tem sido assim realmente. Todavia, não se deve olvidar que em outros, mesmo antes da Revolução de 1930, o nosso incipiente Direito do Trabalho conheceu sua fase de autoafirmação, numa inequívoca demonstração histórica de uma consciência de classe, que já se delineava, desde o início deste século. Ainda aqui temos a confirmação histórica da prioridade cronológica do direito coletivo sobre o individual do trabalho. (GOMES e GOTTSCHALK, 2005, p. 6).

A era Vargas implementa, nas relações de trabalho, uma nova política, intrinsecamente intervencionista e protetiva, assegurando, inquestionavelmente, uma série importante de direitos e vantagens, nas relações de emprego, aos trabalhadores individualmente considerados. Em contrapartida, implementou uma estratégia de atrelamento da organização coletiva dos trabalhadores ao Estado, importando sua cooptação e dominação, ao controlar da criação até a extinção dos sindicatos, ao definir seus objetivos, administração, receitas e eleições. A época, o controle estatal era tão intenso a ponto de a doutrina trabalhista imputar ao sindicato uma nova natureza jurídica: ente de Direito Público, eis que inserto no modelo corporativista autoritário.

Infere-se que o trabalhismo de Vargas inicialmente garantiu aos trabalhadores uma proteção trabalhista inimaginável para a época, considerando a capacidade de organização e conquista do movimento sindical. No entanto, seu preço foi indubitavelmente 
alto, visto que causou a aniquilação do potencial emancipatório da ação coletiva dos trabalhadores, produzindo o chamado "sindicalismo pelego".

\section{ONTOLOGIA TRABALHISTA}

Desta breve gênese, pode-se extrair que o Direito do Trabalho, em termos gerais, representa o regramento das relações de trabalho entre partes desiguais, com a finalidade de atenuar ou diminuir esta hipossuficiência, mediante um sistema jurídico protetivo. A condição de inferioridade ante o empregador foi delineada classicamente por Cesarino Junior, quando caracterizou de hipossuficentes aquelas pessoas nãoproprietárias, que dependem da sua força de trabalho para lograr sua sobrevivência e de sua família:

Aos não proprietários, que só possuem sua força
de trabalho, denominamos hipossuficentes.
Aos proprietários de capitais, imóveis,
mercadorias, maquinaria, terras, chamamos
de hipersuficientes. Os hipossuficientes estão,
em relação aos auto-suficientes, numa situação
de hipossuficiência absoluta, pois dependem,
para viver e fazer viver sua família, do produto
do seu trabalho. Ora, quem lhes oferece
oportunidade de trabalho são justamente
os auto-suficientes [...]. (JUNIOR, 1980,
p. 44-45).

Sua ontos reside na situação fática que a prestação de trabalho é indissociável da condição humana, ensejando uma feição que é, no mínimo, pessoal (trabalho autônomo) e, no máximo, personalíssima (trabalho subordinado).

A natureza personalíssima da relação de trabalho subordinado decorre do fato da impossibilidade de separação entre o trabalho e a pessoa do trabalhador, ou mesmo sua confusão. Nesse sentido, a regulação das relações de trabalho não se deve orientar por cânones civilistas, atinentes ao direito das coisas (res), uma vez que se está regulando diretamente a própria condição humana. Esta circunstância - impossibilidade da separação entre o trabalhador e o trabalho por ele prestado - engendra uma singularidade no Direito Laboral. “A especial singularidade do trabalho como objeto de uma relação jurídica consiste em que, não confundindo-se (sic) com a pessoa que o executa, é no entanto algo pessoal e íntimo, uma emanação, por assim dizer, da personalidade do trabalhador". (OLEA, 1969, p. 142)

Ensinam Orlando Gomes e Élson Gottschalk que o Direito do Trabalho lida diretamente com a condição humana, manifestada na prestação do labor, pois no "contrato de trabalho apanha a própria pessoa, envolvendo-a na sua essência humana. (GOMES e GOTTSCHALK, 2005, p. 12).

Deparando-se, como fora observado na gênese, com situações de excessiva exploração do trabalho humano e diretamente do próprio homem, a ontologia juslaboral foi criada almejando rejeitar a exploração do homem pelo homem, seja por sua atenuação (reformismo cristão), limitação (socialismo útopico), seja mesmo pela supressão (comunismo). Independentemente dos graus de tolerância da exploração, resta clarividente o compromisso ontológico do Direito do Trabalho em questionar a desigualdade entre o patrão (tomador dos serviços) e o trabalhador (prestador dos serviços), ou melhor, em contestar a hipossuficiência nas relações laborais. A desigualdade apontada é a motivadora para o caráter protetivo, segundo Pinho Pedreira: 
O motivo dessa proteção é a inferioridade do contratante amparado em face do outro, cuja superioridade lhe permite, ou a um organismo que lhe represente, impor unilateralmente as cláusulas do contrato, que o primeiro não tem a possibilidade de discutir, cabendo-lhe aceitá-las ou recusá-las em bloco. (SILVA, 1999, p. 22).

É a hipossuficiência que clama por proteção ao trabalhador perante o poderio econômico do seu empregador. Destarte, o fundamento de proteção ao trabalho é a própria proteção à pessoa humana e sua dignidade, uma vez que não há como se separar o trabalho de seu prestador. "Sendo impossível separar o trabalho das pessoas, concretamente considerada, a disciplina inspira-se num personalismo real, humanista e socializante." (CATHARINO, 1982, p. 32)

Assim, as relações de trabalho prestadas a outrem têm como pressuposto, em regra, uma disparidade. Perante a necessidade de sobrevivência, o obreiro não pode livremente estipular as condições contratuais com o tomador de serviços, carece ele, de forma imprescindível, do trabalho. Na lei da oferta e da procura definida ao sabor do mercado, o trabalhador - que não detém os meios de produção - termina por aceitar a subordinação e, especialmente em um contexto de alto desemprego, acolhe o ajuste das condições de trabalho e de remuneração pelo tomador dos serviços, de maneira quase que unilateral. "Se fosse realmente livre para vender (ou não) a sua liberdade, o trabalhador a manteria inviabilizando o sistema. Desse modo, para que o sistema se perpetue, é preciso não só que haja liberdade formal para contratar, mas que falte liberdade real para não contratar." (VIANA, 2004, p. 260).
Na ontologia trabalhista, háoreconhecimento da organização coletiva dos trabalhadores e, principalmente, o reconhecimento dos efeitos ultra-contratuais ou normativos das Convenções Coletivas de Trabalho, delineando uma ruptura com o monismo jurídico e firmando o pluralismo jurídico (WOLKMER, 1999) nas relações de trabalho. Reconhecer uma normatividade advinda dos próprios destinatários (trabalhadores e empresários) representou um processo de abertura do Direito Moderno, impregnado por maior legitimidade e dissonante do tradicional monopólio do Direito pelo aparelho estatal. Saliente-se que os efeitos normativos consectários deste pluralismo jurídico descuram amplos debates acerca da natureza e efeitos da Convenção Coletiva de Trabalho, notadamente pelo seu caráter especial e controverso, bem situado na conhecida expressão de Francesco Carnelutti: "Corpo de contrato, alma de Lei" (apud NASCIMENTO, 2004, p. 1112).

Depreende-se, desse modo, que o Direito do Trabalho surgiu como medida de justiça social - insuflado pelos reclames dos movimentos dos trabalhadores, ideologias socialistas e com valores acolhidos pela classe média, intelectuais e Igreja - para as relações de trabalho que se baseavam em excessiva exploração dos trabalhadores. Essa medida de justiça social se confirma pela mitigação do pilar civilista da autonomia privada, por meio da cogência e imperatividade de uma legislação intervencionista que estipula um rol mínimo de direitos irrenunciáveis. "O Direito do Trabalho surge como conseqüência de uma desigualdade: a decorrente da inferioridade econômica do trabalhador. Essa é a origem 
da questão social e do Direito do Trabalho." (PLÁ RODRIGUEZ, 2000, p. 66).

O Direito do Trabalho surge, então, por uma série de rupturas. A ruptura com a liberdade formal e sua conseqüente autonomia privada. A ruptura com a igualdade praticada após a Revolução Francesa - a igualdade formal, em prol de outra real e efetiva, hodiernamente definida como igualdade material. A ruptura com o individualismo, este que caracterizou o direito moderno como sendo o pilar central do Direito Privado, ao afirmar a coletividade dos interesses e sua força social. A ruptura com o monismo jurídico, recém-fortalecido com o apogeu dos Estados Modernos, a partir do reconhecimento da normatividade advinda das Convenções Coletivas, imputando um pluralismo jurídico nas relações de trabalho. A ruptura com a interpretação clássica do Direito, ao desconsiderar as costumeiras regras de interpretação, em favor da identificação da norma mais favorável, em atenção ao seu compromisso com a proteção do hipossuficiente.

A ontologia trabalhista é intrinsecamente protetiva, eis que só houve razão de ser para esta nova disciplina jurídica, porque a antiga regulação civilista não mais correspondia ao interesses dos atores sociais. O surgimento do Direito Laboral decorre da necessidade de proteção aos hipossuficientes, sendo esta proteção o caractere essencial desta ciência jurídica e, portanto, indispensável.

Conclusivamente, a ontologia trabalhista pode ser sintetizada nas palavras de Martins Catharino:

Nascido e desenvolvido para compensar a desigualdade econômica, mediante desigual e proporcional tratamento jurídico, o Direito do
Trabalho protege os economicamente débeis. os "hipossuficientes", na expressão feliz de A. F. Cesarino Junior. (CATHARINO, 1982, p. 152)

\section{A CRISE DO DIREITO DO TRABALHO}

Situada a gênese e a ontologia, trata-se, agora, de entender o atual cenário do Direito do Trabalho, que tem sido demarcado pela idéia de crise. A compreensão da crise do Direito do Trabalho, em sua integralidade, imprescinde da análise da conjuntura econômica e social que o envolve. Nesse sentido, a série de crises da sociedade contemporânea enseja desdobramentos nas instituições basilares, como o Estado, a Ciência e o Direito. Conseqüentemente, a crise do Direito do Trabalho estará concatenada com a crise que assola a sociedade, já que, sendo o Direito uma Ciência Social Aplicada, refletirá as conseqüências das crises do Estado, da Ciência e do Trabalho.

Aglobalização, norteada pelo neoliberalismo, ao promover as integrações das economias mundiais, também impõe uma redução na atuação estatal. Em verdade, estabelece como diretriz um Estado-Mínimo em contraposição ao Estado-Providência. A autonomia privada ressurge com força, criticando a intervenção estatal que, segundo este pensamento, tem propiciado obstáculos para o crescimento econômico. Este contraste entre um Estado, ainda interventor, mas que sofre reduções, limitações e privatizações provoca uma crise particular do Estado.

Em concomitância, os estudos científicos mais profundos têm demonstrado a própria crise da ciência, especialmente porque têm apontado seus limites. A epistemologia pós- 
moderna desconstrói os mitos científicos da modernidade, quais sejam: o cientificismo e a neutralidade. Vislumbra-se, portanto, uma crise nos paradigmas científicos, que caminham na direção de relativizações, na compreensão de que todo conhecimento é provisório, inconcluso e inacabado, ou seja, de que não existem verdades absolutas e tampouco a ciência, ou melhor, que a racionalidade científica não possui o monopólio na produção de verdades. Tem-se a crise na Ciência, que também repercute no Direito.

Em paralelo com as crises anteriores, a análise dos dados do mercado de trabalho comprova o declínio do emprego. No Brasil, em 2002, havia 27 milhões de trabalhadores empregados (com anotação na CTPS) numa população economicamente ativa de 76,5 milhões de trabalhadores; isso significa que somente $1 / 3$ dos trabalhadores do país estavam protegidos pela tutela trabalhista. Na Região Metropolitana de Salvador, não há muita diferença, pois tem-se atualmente uma taxa de desemprego de 29,7\% da população economicamente ativa, ou seja, de 1,662 milhão de pessoas, 496 mil estão sem emprego.

Verifica-se que a organização da economia global incorre em uma profunda reestruturação produtiva. Segundo Ricardo Antunes (2003, p.182), o modelo de produção fordista é subjugado pelo toytotismo, este fundado na descentralização e terceirização do sistema produtivo, acarretando em uma drástica redução do proletariado fabril estável, na desqualificação conjugada, contraditoriamente, com a especialização, precarização e (ou) subcontratação do trabalho
(ANTUNES, 2003, p. 184). Não se pode olvidar, ainda, que a "crescente transformação da ciência em força produtiva" (SANTOS, 1999, p. 200) tem resultado no fenômeno do desemprego estrutural, a exemplo dos postos de trabalhos sucumbidos pela automação, informática e robótica.

Nesse sentido, as novas modalidades de trabalho têm sido utilizadas dentro da estratégia geral pós-fordista de extenalização. O fenômeno da externalização ou out-sourcing representa o intento do paradigma pós-fordista em evair-se das obrigações trabalhistas, a partir de novas formas de trabalho. A crise do emprego, então, não pode ser explicada unicamente pelos fenômenos econômicossociais supracitados. É assentada, também, na explícita pretensão flexibilizadora e desregulamentadora. Poder-se-ia argumentar que a crise do emprego justifica-se pela existência da proteção tutelar estatal nesta relação de trabalho, enquanto que nas outras prevalece a máxima liberalidade das partes. A reconfiguração do trabalho objetiva, além dos ganhos produtivos, a evasão da proteção peculiar do Direito do Trabalho. Perante a crise do emprego, o sistema protetivo trabalhista urge ser repensado, sob pena de não conseguir oferecer proteção ao trabalhador contemporâneo.

Tal realidade indica a reconfiguração do trabalho na sociedade. O processo econômico-social de reorganização das formas de trabalho é chamado de reestruturação produtiva. $\mathrm{O}$ crescimento e a criação de formas de trabalho sem proteção legal, tais como o trabalho informal, subemprego, trabalho (falsamente) cooperado e os trabalhadores pseudo-autônomos 
desvela a pretensão de fuga da relação de emprego. Dessa forma, a nova organização do trabalho está plenamente associada à crise do emprego, que pode ser chamada, de outra maneira, de crise do trabalho.

O mundo do trabalho é atualmente caracterizado pela heterogeneização das formas de trabalho, particularmente com o decréscimo do trabalho classicamente assalariado, o emprego. Frise-se que a redução do emprego, em favor de relações precarizadas ou supostamente autônomas, importa em exclusão de um imenso contingente de trabalhadores do sistema protetivo trabalhista, social e previdenciário. Esse novo mundo do trabalho criou, conseqüentemente, uma classe trabalhadora, assim definida por Antunes:

Essas mutações criaram, portanto, uma classe trabalhadora mais heterogênea, mais fragmentada e mais complexificada, dividida em trabalhadores qualificados e desqualificados do mercado formal e informal, jovens e velhos, homens e mulheres, estáveis e precários, imigrantes e nacionais, brancos e negros etc., sem falar nas divisões que decorrem da inserção diferenciada dos países e de seus trabalhadores na nova divisão internacional do trabalho. (2003, p. 184)

Todas essas circunstâncias provocam reflexos importantes no Juslaboralismo, pois implicam redução da atuação legiferante do Estado, na redução de custos - redução de direitos e fragmentação da classe trabalhadora. De fato, o Direito do Trabalho termina sendo o direito de poucos trabalhadores. Pode-se até denominá-lo Direito do Emprego ou, como já ensinava Martins Catharino (1979), "Contrato de Emprego", inclusive porque o Direito Laboral foi construído a partir do emprego típico (ROMITA, 2000, p. 188).

\section{REAFIRMANDO O PRINCÍPIO DA PROTEÇÃO}

Não obstante as mudanças advindas da transição pós-moderna e do pós-fordismo, as condições de vida do trabalhador continuam a ser demarcadas pela debilidade. A análise de três importantes elementos do mercado de trabalho comprovam a persistência da hipossuficiência. São o percentual de desempregados, o rendimento salarial e as novas formas de trabalho (ou trabalho informal). Sublinhe-se que o heterogêneo (diferente da relação de emprego) implica, do ponto de vista técnico trabalhista, a exclusão da proteção.

A ontologia juslaboral não se esvai ante o mundo em transição pós-moderna e a fábrica pós-fordista. A condição do trabalhador, não mais do empregado, persiste no contexto da dependência ou hipossuficiência. Há que se vislumbrar de maneira indissociável o binômio hipossuficiência-dependência, que implica a defesa de um Direito do Trabalho de cunho protetivo enquanto seus destinatários perdurarem numa situação de desigualdade econômica. "Existirá, pois, a necessidade de proteção enquanto esta existir [inferioridade dos trabalhadores], mas deve ser evitada a superproteção, que pode produzir efeitos perversos.” (SILVA, 1999, p. 39).

Cumpre, de igual modo, rechaçar alguns argumentos propalados como causadores da suposta crise do princípio da proteção.

Trata-se de uma repetição (disfarçada) dos argumentos contrários ao surgimento do Direito do Trabalho e dos seus princípios. Contudo, ao invés de se invocar o argumento da liberdade das partes (superado pela idéia de hipossuficiência), o discurso (neo) 
liberal vale das idéias de competitividade e eficácia, como também repetem-se as de leis do mercado, necessidade de baixar custos, entre outras. O sentido implícito de movimento de liberalização ao retirar o teor protetivo do Direito Laboral é retomar uma regulamentação civilista das relações de trabalho, em mitigando o princípio préjurídico ou axioma de que o trabalho não é mercadoria, como adverte Pinho Pedreira:

É preciso reconhecer que cada norma do Direito do Trabalho constitui um acidente, um obstáculo, um impedimento para tratar o trabalho como uma mercadoria sujeita às leis do Mercado. Querer tirar as rigidezes equivale a querer destruir o Direito do Trabalho. (SILVA, 2004, p. 93).

A crise econômica, fundamento de igual importância, para que se pretenda uma flexibilidade na proteção dos trabalhadores, sempre acompanhou o Direito do Trabalho. $\mathrm{Na}$ história, constatam-se inúmeras crises econômicas internacionais e nacionais, que repercutiram, inclusive com o afrouxamento da rigidez da legislação trabalhista, sem, contudo eliminar a ontologia protecionista (SILVA, 1999, 38). Além disso, mesmo nos momentos críticos, os interesses econômicos não podem subjugar o valor social do trabalho, isto é, não podem, para lograr a recuperação, aviltar as condições de trabalho dos trabalhadores, diminuindo a proteção. Transferir os prejuízos econômicos para os trabalhadores implica a negação do princípio da forfertaridade, que desvincula os riscos do negócio dos direitos trabalhistas.

De forma diametralmente oposta, em momentos de crise que se deve recorrer às bases e diretrizes do fenômeno contestado. Recorrer às diretrizes importa reafirmar os princípios originários, que são, pelos seus caracteres, os componentes da disciplina jurídica com maior perenidade, uma vez que são depositários de todos os substratos (econômicos, sociais e políticos) que originaram o sistema em catarse. Constatada a similitude da situação econômica - na perspectiva de dependência econômica do trabalhador, inclusive agravada em alguns casos - a confirmação do valor social da proteção aos trabalhadores se impõe. Porém, as contestações liberais negam este raciocínio, advogando a existência de um único caminho: a liberalização.

Nessa perspectiva, Amauri Mascaro Nascimento defende a necessidade a intervenção estatal (uma das técnicas protetivas), mesmo perante a crise econômica e social, demarcada pela ascensão da flexibilização e precarização:

[...] a resposta é afirmativa porque a verdadeira igualdade está em tratar desigualmente situações desiguais. No entanto, há direitos que devem ser defendidos com a força da lei e outros que podem ser melhor disciplinados pela autocomposição direta entre os próprios interessados. (NASCIMENTO, 2002, p. 905)

Em atenção ao contexto crítico, a OIT se manifestou, por meio da Declaração de 1998 sobre princípios e direitos fundamentais no trabalho, reconhecendo que os direitos fundamentais atualmente são:

a) Liberdade sindical e reconhecimento efetivo da negociação coletiva;

b) Eliminação de todas as formas de trabalho forçado ou obrigatório;

c) Abolição efetiva do trabalho infantil;

d) Eliminação da discriminação em matéria de emprego e ocupação. 
Infere-se da Declaração da OIT de 1998 uma ênfase ao plano coletivo, bem como nas questões de excessiva exploração sequer aceitas no capitalismo (trabalho forçado e infantil) e, destaque-se, menção à defesa da isonomia nos empregos e ocupações. Apesar de não haver referência explícita ao princípio da proteção, o caráter tutelar do Direito Laboral pode ser depreendido das declarações anteriores e da própria finalidade da OIT. Noutro sentido, verifica-se que, com a menção à isonomia entre emprego e "ocupação" estipula-se um regime de igualdade entre o trabalho convencional (emprego) com as atuais formas flexíveis (flex-jobs, trabalho a tempo parcial, parassubordinados, cooperados, entre outros), ratificando a noção de expansionismo do Direito do Trabalho, intrinsecamente protecionista.

Reafirmada a perspectiva protecionista, o princípio da proteção precisa de reforço para enfrentar seus dilemas contemporâneos. A corrente compreensão normativa e vinculante dos princípios, notadamente dos princípios constitucionais, pode em muito colaboar. Trata-se de absorver na doutrina ascendente o papel dos princípios e transpô-lo para o princípio protetivo laboral.

Em consonância com a postura protecionista delineada, sustenta-se que o Direito do Trabalho urge em ser repensado, com o objetivo de conferir maior efetividade na proteção aos empregados e ampliar-se para ofertar proteção aos trabalhadores heterogêneos e diferenciados, desde que dependentes. A ampliação da tutela para os parassubordinados, mesmo que em doses menores do que aquelas destinadas ao empregado, é hermenêutica que mais concretiza e torna viva a Constituição, pois significa "a concretização na práxis jurídica entre nós do humanismo e da axiologização nas relações de trabalho, imperativos de impressão da justiça nestas relações, postulado da ordem e da paz sociais." (JUCÁ, 2000, p 109). A título de exemplo vale conhecer a recente experiência italiana que criou o Contrato a Projeto, como horizonte de perspectivas.

\section{PROTEÇÃO VERSUS REGULAÇÃO}

Há que se fazer uma severa crítica à ontologia protetiva trabalhista, em atenção à pré-compreensão orientada pelo materialismo histórico.

Numa análise mais detida, sabe-se que a proteção trabalhista articulada na legislação conforma-se como mecanismo de dominação, porque assegura a continuidade da exploração do trabalhador, advinda da apropriação do resultado do trabalho por conta alheia. Com as medidas protetivas que asseguram alguns direitos, mas mantém a mais-valia, o Direito do Trabalho funciona como conservador do status quo, impedindo as pretensões revolucionárias dos trabalhadores. É este o sentido apurado da afirmativa de Palomeque López:

[...] a legislação do trabalho corresponde prima facie a uma solução defensiva do Estado Burguês para, através do de um corpo de normas tuitivas a favor dos trabalhadores, dispor sobre a integração e institucionalização do conflito entre o capital e o trabalho em termos compatíveis com a viabilidade do sistema estabelecido. (apud ROMITA, 1998, p. 603)

Proteger significa dominar e colocar, sob o julgo do protetor, o protegido que, graças à sua condição de dependente, iráse satisfazer com a qualidade de protegido. Destaca Pinho Pedreira: 
Pareceu-nos sempre que em tempo algum o fim, em última instância, do Direito do Trabalho foi a proteção do trabalhador, pois não seria possível a existência, no regime capitalista, de um ramo do direito em contradição com os interesses da classe dirigente, [...]. Para nós, ontem como hoje, a finalidade imediata do Direito do Trabalho é a proteção do trabalhador, mas a finalidade mediata o equilíbrio social ou, como se exprime como maior propriedade Wolfgang Daubler, "a conservação dos status quo social”. (SILVA, 1999, p. 34).

No mesmo sentido, Aldacy Rachid Coutinho discorre criticamente que "a proteção do trabalhador é um mito. Aquilo que está no lugar do que não pode - ou não deve - ser dito. Está enunciar que protege, quando nem sempre tutela. Afinal o direito do trabalho é o direito capitalista do trabalho." (COUTINHO, 2001, p. 7).

Não obstante, mesmo o princípio da proteção conduzindo a uma faceta de dominação pela regulação, não se pode deixar de defendê-lo, particularmente de defender seu caráter protetivo. Seu caráter instrumental também poderá ser guiado pelo viés emancipatório, quando se vincula a proteção à condição de dignidade do homem trabalhador, e quiçá para além daquela reconhecida pelo direito positivo. Aldacy Rachid Coutinho assevera:

E se não fosse protetivo do trabalhador ... seria do capital. A primazia do trabalho sobre o capital determina que o direito está pelo e para o homem. O homem não está a serviço dos interesses traduzidos no direito. O mercado não pode influenciar, direcionar o direito do trabalho. (COUTINHO, 2001, p. 7).

A tensão cotejada da regulaçãoemancipação atinge, de igual maneira, o direito. Apesar do direito hegemônico praticado, ensinado dogmaticamente e dito servir como meio de conservação social (técnica de regulação social), tem-se o contra-direito, o Direito Crítico, insurgente, de combate, surrealista, ou qualquer outra denominação que expresse movimentos, no âmbito do direito de reação à dominação daquele direito posto e hegemônico, na direção compromisso libertário. Não obstante a indispensável crítica materialista, a defesa de um direito protecionista é pauta, no regime capitalista, das ideologias reformistas e revolucionárias.

O cenário que se conjectura para a projeção do Direito do Trabalho resgata seu horizonte fundador. Rejeita-se uma postura liberalizante, eis que a flexibilização negociada ou a precarização das condições de trabalho não são compatíveis com a ontologia juslaboral, e, no plano fático, não apresentam resultados de atenuação/diminuição da hipossuficiência do trabalhador, que continua dependente, seja na subordinação, autonomia ou parassubordinação. De outro modo, o insucesso da vertente conciliatória européia, denominada flexicurity, aponta para o retorno da proteção, desde que baseada em outros moldes. Esta leitura conduz a uma superação da crise e a reafirmação do Princípio da Proteção. Assim conclui Plá Rodriguez:

Deve continuar fiel a seus princípios, aplicando-os adequadamente à época e às realidades efetivas que se põem em cada momento. Essa aplicação racional, razoável, funcional dos princípios deve distinguir o permanente do circunstancial, separar o essencial do contingente. Os princípios não são obstáculo às mudanças exigidas pelos tempos e pelas circunstancias. Sua própria maleabilidade lhes permite manter a substancia mesmo que tudo o mais se mude. (PLÁ RODRIGUEZ, 2000, p. 82). 
Os discursos flexibilizantes, hegemônicos na globalização, não se sobrepõem à realidade social, que persiste em caracterizar o trabalhador de hipossuficiente. O modo de produção pós-fordista, apesar de alterar as formas de trabalho e seus contratos, tem agravado a exploração e a dependência econômica do trabalhador. A crise do princípio da proteção não conduz à sua negação, mas engendra uma necessidade de repensá-lo.

Nesta tensão regulação-proteção, é tático defender, na sociedade capitalista, um Direito do Trabalho protetivo, que opera com fundamentos que negam a racionalidade jurídica capitalista, como a autonomia privada em favor de um humanismo que não admite que o trabalho humano seja tratado como mercadoria. O ideal de Justiça Social e combate à exploração, bases do Direito do Trabalho, confirmam, em grande medida contra-racionalidades dentro do sistema jurídico dominante, aproximando mais o juslaboralismo de uma vertente emancipatória do que regulatória.

Contudo, o caminho que se segue, pela sua complexidade imanente, diferenciação e heterogeneização, traz um horizonte que privilegia individualidades ou individualismos, relegando a atuação coletiva ao declínio e ao descrédito. Neste percalço, Carlos Drummond de Andrade adverte:

Estou preso à vida e olho meus companheiros.

Estão taciturnos mas nutrem grandes esperanças.

Entre eles, considero a enorme realidade O presente é tão grande, não nos afastemos. Não nos afastemos muito, vamos de mãos dadas.

(ANDRADE, 2005, p. 59)
Trata-se de, utopicamente, desvelar que a proteção que se almeja ao trabalhador não deve depender exclusivamente das medidas intervencionistas do Estado, o que configuraria a vitória de uma (des)proteção regulatória com perversos excessos sobre uma proteção emancipatória, ou seja, o primado da outorga (e controle) sobre a conquista. Ao contrário, a perspectiva que se coloca é resgatar, na história companheira, a importância fundante da atuação coletiva na luta pela proteção nas relações de trabalho.

Aliás, o companheiro, vindo de longe das associações de companheiros e oficiais da Idade Média (compagnonnages), designa aquele que reparte o pão. Ou seja, aquele que compartilha as mesmas condições de trabalho (com o outro trabalhador), sabendo que somente juntos, partilhando sofrimentos (consciência coletiva), poderão contrapor-se ou resistir fraternamente.

Essa perspectiva irrompe e recompõe dois valores fundantes e basilares do Direito do Trabalho, que são recuperados no contexto contemporâneo, e, por isso, indispensáveis para a tarefa do repensar. São a fraternidade, que atrai o perfil protetivo nas relações enfocadas individualmente entre trabalhador e empregador; e a consciência de classe, que ressalta a imprescindibilidade de um ente coletivo renovado para os problemas hodiernos.

Faz-se necessário explicitar a idéia de renovação do sindicato. Reconhecida a crise do sindicalismo, consectária da crise do Direito Laboral acentuada pelos fenômenos do desemprego estrutural e da terceirização, poder-se-ia abandonar a entidade de classe, acaso entenda-se que os conflitos de classe já foram superados pelas atuais relações de 
trabalho. É esta a propaganda da nova relação interativa de parceria empregado-empresa.

De outro lado, do materialismo dialético, que dirige epistemologicamente a pesquisa, cumpre negar o discurso do fim dos conflitos de classes e reforçar a atuação coletiva, a partir da autocrítica acerca dos instrumentos, recursos e atitudes sindicais que não foram aptos para enfrentar os atuais conflitos capitaltrabalho. Impõe-se produzir novas práticas sindicais que aglutinem outros sujeitos (sociedade civil, consumidores, movimentos populares) no conflito trabalhista. É preciso construir atitudes e representações tão heterogêneas como são heterogêneos os trabalhadores atuais, conquanto mantenha-se a centralidade da questão do trabalho (ANTUNES, 2003).

Por fim, uma leitura emancipatória sinaliza para a conclusão de que é preciso manter o caráter protetivo do Direito do Trabalho. Além disto, é indispensável um sistema sindical que consagre e torne efetiva a liberdade sindical, iniciando-se pela ratificação da Convenção 87 da OIT e a adoção de medidas que combatam as ações anti-sindicais.

Desse modo, a proteção trabalhista expressa um compromisso com a emancipação dos trabalhadores, conquanto seja proveniente de uma legislação intervencionista e expandida (ou reforçada) pela atuação coletiva de sindicatos livres e representativos. Defender, nestes moldes, a proteção é uma tática adequada à sociedade capitalista, mesmo reconhecendo sua função de conversação do status quo sobre uma efetiva emancipação dos trabalhadores. Trata-se de explorar as possibilidades insurgentes do sistema até seus limites. Em verdade, uma real proteção-emancipação dispensaria o Direito do Trabalho o que, por ora, não está a acontecer, justificando o caráter protetivo do juslaboralismo.

\section{REFERÊNCIAS}

ANDRADE, Carlos Drummond. Sentimento do mundo. 7.ed. Rio de Janeiro: E. Record, 2005.

ANTUNES, Ricardo. Adeus ao Trabalho? 7.ed. São Paulo: Cortez, Universidade Estadual de Campinas, 2003.

CATHARINO, José Martins. Direito do Trabalho: Estudos, ensaios, pesquisas. Rio de Janeiro: Edições Trabalhistas, 1979.

CATHARINO, José Martins. Compêndio de Direito do Trabalho. São Paulo: Saraiva, 1982. v.1.

COUTINHO, Aldacy Rachid. O princípio da proteção revistado. Revista Bonijuris. v.13. Curitiba: Bonijuris, jul. 2001.

CUEVA, Mário De La. Panorama do Direito do Trabalho. Porto Alegre: Editora Sulina, 1965.

DELGADO, Maurício Godinho. Curso de Direito do Trabalho. 4.ed. São Paulo: LTr; 2005. GADAMER, Hans-Georg. Verdade e método. 7.ed. Trad. de Flávio Paulo Meurer. Petrópolis: Vozes, 2005.

GENRO, Tarso. Crise da Democracia. Petrópolis: Vozes, 2002.

GOMES, Orlando, GOTTSCHALK, Élson. Curso de Direito do Trabalho. 17.ed.

Atualizada por José Augusto Rodrigues Pinto e Otávio Augusto Reis de Sousa. Rio de Janeiro: Forense, 2005.

JUCÁ, Francisco Pedro. A constitucionalização dos Direitos do Trabalhadores e a

Hermenêtica das Normas Infraconstitucionais. São Paulo: Ltr, 2000.

JUNIOR, Cesarino. Direito Social. São Paulo: Ltr, Universidade de São Paulo, 1980;

MARX, Karl e ENGELS, Friedrich. Ideologia Alemã, Coleção Clássicos Filosofia/Ciências Sociais. São Paulo: Ed. Martins Fontes, 1996. 
MARX, Karl. Manuscritos econômicosfilosóficos e outros textos escolhidos/ Karl Marx. Coleção os Pensadores. 2.ed. São Paulo: Abril Cultural, 1978.

NASCIMENTO, Amauri Mascaro. Curso de Direito do Trabalho. 19.ed. São Paulo: Saraiva, 2004.

NASCIMENTO, Amauri Mascaro. O novo âmbito do protecionismo do Direito do Trabalho. São Paulo: LTr, Revista de Agosto/2002.

OLEA, Manoel Alonso. Introdução ao Direito do Trabalho. 2.ed. Ed. Porto Alegre: Sulina, 1969.

OLIVEIRA, Murilo Carvalho Sampaio. Repensando o Direito do Trabalho. Jornal A Tarde, Salvador, 17 out. 2004, Judiciárias.

PLÁ RODRIGUES, Américo. Princípios do Direito do Trabalho. 3.ed. São Paulo: Ltr, 2000.

PINTO, Rodrigues. Curso de Direito Individual do Trabalho. 3.ed. São Paulo: LTr, 1997.

ROMITA, Arion Sayão. A flexibilização e os princípios do Direito do Trabalho. In: Direito do Trabalho: Temas em Aberto. São Paulo: LTr, 1998.

ROMITA, Arion Sayão. A flexibilização das leis do Trabalho em debate: choque e correntes. In: FILHO FRANCO, Georgenor de Souza (Org.). Presente e Futuro nas Relações de Trabalho. São Paulo: LTr, 2000.
SILVA, Luiz Pinho Pedreira de. Principiologia do Direito do Trabalho. São Paulo: LTr, 1999.

SILVA, Luiz Pinho Pedreira de. O estado atual dos princípios do direito do trabalho. In: Revista do Programa de Pós-graduação em Direito da UFBA/Faculdade de Direito. Salvador: Faculdade de Direito: EDUFBA, 2004.

SOUZA JR, José Geraldo Junior (Org.). Série o Direito achado na rua. Uma introdução crítica ao Direito do Trabalho. Brasília: Universidade de Brasília, 1993. v.2.

SOUSA SANTOS, Boaventura de. Pela Mão de Alice: o social e o político na pós-modernidade. 6.ed. São Paulo: Cortez Editora, 1999.

SÜSSEKIND, Arnaldo. Curso de Direito do Trabalho. Rio de Janeiro: Renovar, 2004.

SÜSSEKIND, Arnaldo, et al. Instituições de Direito do Trabalho. 8.ed. Rio de Janeiro: Frei Bastos, 1981.

VIANA, Márcio Túlio. Proteção Social do Trabalhador no Mundo Globalizado. In: PIMENTA, José Roberto Freire (Org.). Direito do Trabalho: evolução, crise, perspectivas. São Paulo: LTr, 2004.

WOLKMER, Antônio Carlos. Pluralismo Jurídico: Fundamentos de uma Nova Cultura no Direito. 2.ed. São Paulo: Alfa Ômega, 1997. 